\title{
Monetary Policy Transmission in Financial Markets: The Case of India
}

\author{
Suvojit Lahiri Chakravarty \\ Associate Professor, Aryabhatta College, University of Delhi, Benito Juarez Road, \\ New Delhi - 110021, India; suvojit50@gmail.com
}

\begin{abstract}
The paper looks into the monetary policy transmission across different segments of the financial market in India from May 2011 to March 2018. It studies the effect of two instruments of monetary policy i.e., policy rate and a composite index (score) comprising of quantity instruments and policy rates on the money market, government securities market, foreign exchange market and the stock market using VAR analysis. The results show that monetary transmission is fairly quick in the money market and other interest rates of short maturity compared to interest rates of longer maturities. The impact on exchange rate is an appreciation for the policy rate but a depreciation followed by an appreciation for the composite index. Lastly the effect of policy rate and composite index on the sensex is negative.
\end{abstract}

Keywords: Financial Markets, Monetary Policy Transmission

JEL classification: E52, E58

\section{Introduction}

An efficient and integrated financial market is an important infrastructure that boosts saving, investment and economic growth 1 . This takes place through a variety of ways such as increasing investor's opportunities for portfolio diversification, lowering costs of investment, improving resource allocation, consumption smoothing etc. However increasing financial integration can also expose a country to certain types of risks namely risk of excessive volatility in financial markets, abrupt reversals in capital flows, macroeconomic instability etc.

India has taken a large number of measures to liberalise the financial sector over the years. These include deregulation of the interest rate, development of the secondary market for several instruments, adoption of a flexible exchange rate, move towards uniform banking etc. These measures have facilitated financial market integration in India ${ }^{2}$.

An integrated financial market facilitates effective monetary policy making. The reason is when financial integration exists, policy intervention by the monetary authorities at one end of the market is quickly transmitted to the entire spectrum of the market ${ }^{3}$. In this regard the Reserve Bank of India (RBI) has progressively shifted from quantity based instruments (broad money) to price based instruments (interest rates) for effective policy making.

Monetary policy in India has undergone a sea change over the last thirty years. The monetary targeting approach (1986) gave way to the multiple indicator approach (1998) which was fine-tuned through the Liquidity Adjustment Facility (LAF) (June 2000). This was upgraded in May 2011 following the recommendations of the Working Group constituted by the RBI.

There are a lot of studies analysing monetary transmission across different segments of the financial market in the LAF era ${ }^{2,6,6}$. Our aim in this paper is not only to look into the effect of policy rate changes but also the effects of changes in quantity instruments such as Cash Reserve Ratio (CRR) \& Statutory Liquidity Ratio (SLR) on interest rates of different maturities in the LAF regime using monthly data from May 2011 through March 2018. The other motivation of our study is that although 
many research papers exist prior to this period, there is a paucity of studies looking into this aspect after May 2011 i.e., after the RBI has made the changes in the LAF policy framework keeping in mind the recommendations of the Working Group.

The rest of the paper is organised as follows. Section 2 provides a review of the literature. In section 3 an overview of the monetary operating procedure followed by the RBI over the years is provided. Section 4 discusses price based and quantity based instruments followed by the RBI. In section 5 a brief summary of the VAR methodology is provided. Section 6 discusses the results and finally section 7 concludes the study.

\section{Literature Review}

Among the earliest papers on integration of financial markets for the Indian economy is that of Bhoi \& Dhal $(1998)^{4}$. This paper looks into the convergence of interest rates of various maturities across different markets. They find that there exists some convergence of interest rates in the money, credit and govt. securities market but the capital market exhibits isolated behaviour. The relationship between domestic and foreign interest rates show that there is some evidence of covered interest rate parity in the Indian economy.

Jain and Bhanumurthy (2005) $)^{5}$ analyse the issue of integration of financial markets in India with international markets during a period of high capital flows. The results show that there is a presence of long run relationship between call money market (CMR) and London interbank offer market (LIBOR). The relationship between Rupee/ US dollar exchange rate (ER) and LIBOR although exists is relatively weak. The authors conclude that the short term money market is integrated with the international financial market and there is no robust integration between the domestic foreign exchange market and the foreign market.

Bhattacharya and Sensarma (2007) ${ }^{6}$ study the relative efficiency and robustness of alternative monetary policy instruments in communicating policy signals in financial markets. They consider both the pre LAF and the post LAF period.

The policy instruments included in the pre LAF period are Bank Rate (BR) and Cash Reserve Ratio (CRR). The impact of $\mathrm{BR}$ on all the financial markets is found to be very significant and the impact of CRR is significant in the foreign exchange market.

In the post LAF period in addition to the BR and CRR, the reverse repo rate (R Rate) is considered. The results show that only the impacts of CRR \& R Rate on call are positive and significant. The impact of $R$ Rate on one year govt. securities is marginally positive whereas that of CRR \& BR is negligible.

Bhattacharya et al., (2009) $)^{7}$ study the interaction of the money market microstructure and the operating framework of monetary policy. The authors consider four segments of the money market viz., the interbank call market, the 91 day, 182 day and the 364 day T bill market. The empirical exercise focusses on the interaction between the bid ask spreads and monetary policy announcements and turnover in each market segment.

The results show that the call market, turnover, CRR announcement effects, and lagged bid ask spreads are statistically significant with the expected signs. For the $\mathrm{T}$ Bills market policy rates are significant except for the 364 day $\mathrm{T}$ bill market whereas the CRR announcement effect is significant except for the $91 \& 182$ day segments. Lastly volatility persistence in all the markets is borne out by the significant lagged effects.

Singh (2011) looks into the presence of asymmetry in the monetary policy transmission across different segments of the financial market. The evidence shows that the transmission of monetary policy changes is more prompt in the short term money market compared to the long term financial market. There is a greater pass through from policy rates to money market rates during a deficit liquidity condition compared to a surplus one. There is greater persistence of policy rate shocks on deposit rates as compared with lending rates due to the importance of other explanatory factors like fiscal position of the govt. inflationary expectations etc.

The RBI (2011) $)^{9}$ study examines the effects of policy rate shocks on financial variables. It considers both liquidity deficit period when the repo rate is the relevant policy variable and the liquidity surplus period when the reverse repo rate is considered to be the same. The results show that the impact of policy rate changes is different across the various segments of the financial market. The money market responds most quickly to changes in the policy rate. The transmission mechanism is more effective in a deficit liquidity situation than in a surplus situation. 
Ray \& Prabhu (2013) ${ }^{2}$ in their paper address two questions - (a) what is the nature of integration among different segments of Indian financial markets and (b) what has been the influence of monetary policy on different segments of financial markets. The results indicate that the transmission of monetary policy works well in the call money rate. There is also evidence of transmission of monetary policy shocks in the other financial markets except the stock market. The study finds that the money market segment is fairly integrated. Government securities and corporate bond markets are somewhat integrated. There is less integration between money market and stock market and the same conclusion holds true between money market and forex market.

Patra et al., (2016) $)^{\frac{13}{3}}$ analyse the pass through from policy rate to the operating target i.e., the weighted average call money rate across different regimes of the LAF. It is seen that the long run coefficient on the effective policy rate is close to unity. The short run dynamics captured by the error correction term show that the speed of adjustment has progressively increased over the years. This the authors attribute to the introduction of intraday fine tuning operations of the RBI leading to better liquidity management by banks.

Most of the studies on the Indian economy find that financial market integration is strong especially at the short end of the market and then it progressively spreads across interest rates of longer maturities.

\section{Monetary Operating Procedure}

The RBI followed the monetary targeting framework with feedback as recommended by the Chakravarty Committee during the mid-eighties. This was followed by the multiple indicator approach, introduced in April 1998, which had an emphasis on the interest rate channel of monetary transmission. This was criticised as it did not provide for a clearly defined nominal anchor for monetary policy.

The LAF was introduced in June 2000 as a part of the outcome of the Narasimham Committee on Banking Sector reforms of 1998 to manage market liquidity on a daily basis and also to transmit interest rate signals to the market. The LAF was operated through overnight fixed rate repo and reverse repo which provided an informal corridor for the call money rate (RBI, 2011) $)^{9}$. This helped to develop interest rate as an instrument of monetary transmission. However it suffered from two weaknesses. First, there was a lack of a single policy rate as the operating policy rate alternated between repo (during deficit liquidity situation) and reverse repo (during surplus liquidity situation). Second there was a lack of a strict corridor as the overnight call rate sometimes breached the upper or lower limit in extreme deficit or surplus conditions.

To address these shortcomings, a new operating procedure was introduced in May 2011. It included some new features. First the weighted average overnight call money rate was explicitly recognised as the operating target of monetary policy. Second the repo rate was made the only policy rate. Third, a new Marginal Standing Facility (MSF) was instituted under which scheduled commercial banks (SCBs) could borrow overnight at 100 basis points above the repo rate upto one percent of their net demand and time liabilities (NDTL). The limit was subsequently raised to two percent of NTDL. Fourth the revised corridor was defined with a fixed width of 200 basis points. The repo rate was placed in the middle of the corridor, the reverse repo rate at 100 basis points below it and the MSF, Bank rate 100 points above it. Lastly the Bank Rate which had remained unchanged since 2003 was alligned to the MSF rate in February 2012.

In September 2014 the RBI undertook some reforms in the new LAF which comprised of putting an end to unlimited accommodation of liquidity needs at the fixed repo rate, provision of the predominant portion of the central bank liquidity through term repo auctions etc.

The main limitations of the new LAF framework were (a) this was based on the central premise of keeping the system in a deficit mode and so the transmission of policy rate cuts in the easing phase remained incomplete and (b) monetary policy tightening via increase in repo rate was sometimes followed by liquidity easing measures like lowering the Cash Reserve Ratio (CRR) which made the policies inconsistent.

\section{Price Based and Quantity Based Instruments}

The discussion in the previous section makes it clear that the RBI uses both price based as well as quantity based instruments for the conduct of its monetary policy. 
Among the price based instruments, repo and reverse repo rates were announced separately till May 2011. Thereafter the repo rate is the only policy rate and the reverse repo rate is linked with the repo rate.

The CRR and the SLR were the main quantity instruments used by the RBI. To see how price and quantity instruments were used during the sample period, we use the price instrument (repo rate) and construct composite measures for quantity instruments following the approach of Das (2015) $)^{10}$. The quantity instrument is taken to be the sum of CRR \& SLR. Figures (1) \& (2) show that price and quantity instruments have generally moved in the same direction with exceptions for brief episodes during the sample.
The exception is between 2011 \& 2012 where the two instruments have moved in the opposite direction. This implies that the RBI has also used quantity based instruments in framing monetary policy.

To address this problem we have constructed a measure of the overall stance of monetary policy (Score) following Das et al., (2015) $)^{10}$. Scores of $0,+1,-1$ are assigned if there is no change, an increase or a decrease in the values of individual instruments respectively. The overall stance of monetary policy is calculated by taking an unweighted sum of the scores of the individual instruments. Figure 3 shows the pattern of the score based measure of the overall stance of monetary policy.

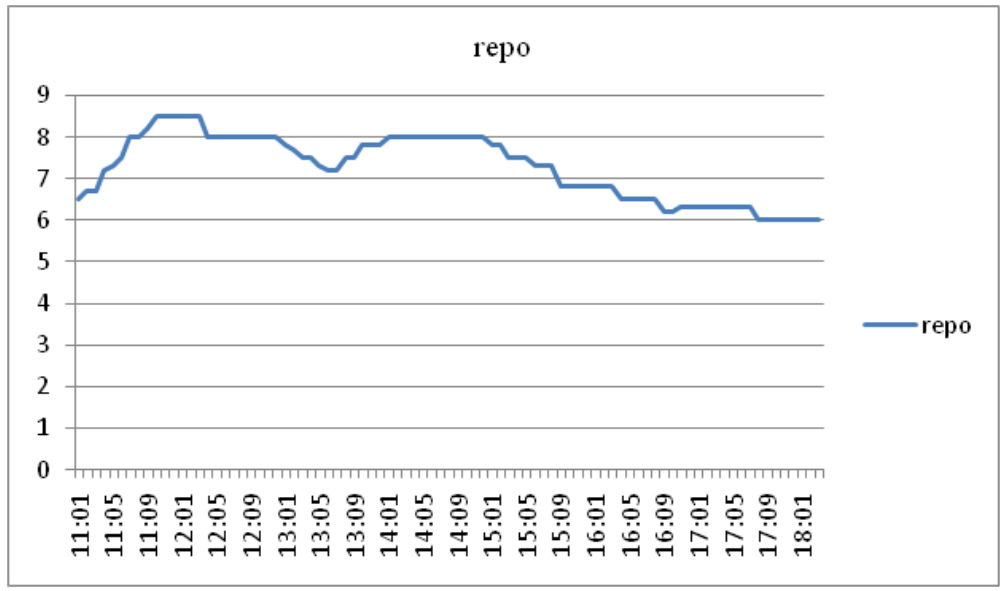

Source: Hand book of Statistics of the Indian economy.

Figure 1. Monetary Policy, Price Instruments.

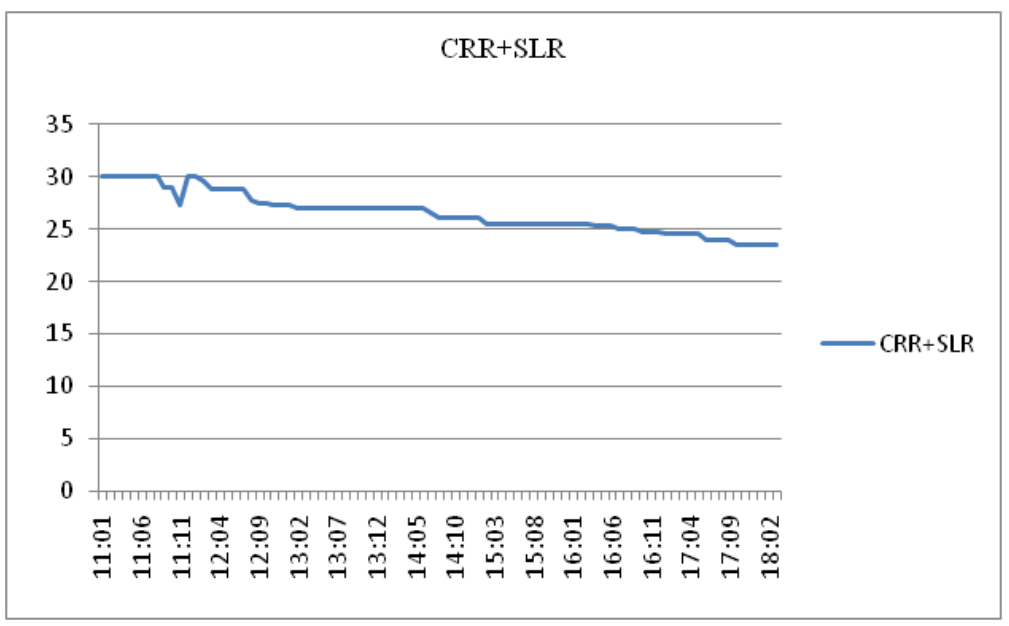

Source: Handbook of Statistics for the Indian economy.

Figure 2. Monetary Policy, Quantity Instruments. 


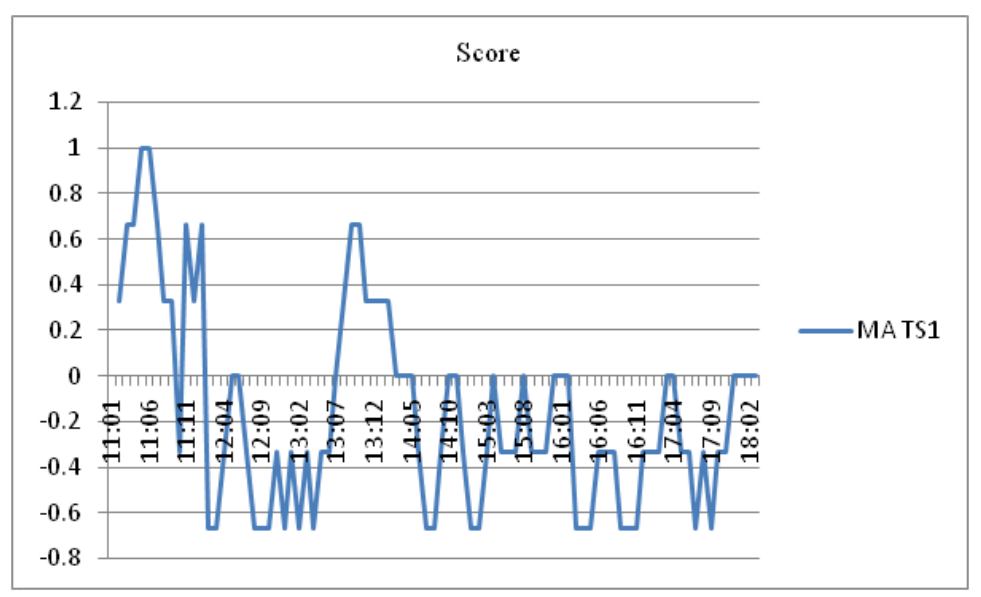

Source: Handbook of Statistics of the Indian Economy and Author's calculations.

Figure 3. Overall Stance of Monetary Policy, Score Based Index (3 month moving average).

\section{Methodology: Vector Autoregression (VAR) Analysis}

In the paper we analyse monetary transmission across financial markets for the Indian economy. The time period of our study is from May 2011 through March 2018. The starting point is selected at the onset of the new LAF regime.

We construct a Vector Autoregression model using monthly data on the following variables:

(1) Policy variable comprising of either

(a) Price based instruments i.e., Repo rate (RR) or

(b) Overall stance of the monetary policy (Score).

(2) Weighted average call money rate (CMR)

(3) One year Government securities (GS1)

(4) Ten year Government securities (GS)

(5) Rupee-dollar spot exchange rate (EX)

(6) Bombay Stock Exchange Sensitive Index in logarithmic form (LSen).

We have decided to include two policy variables i.e., Repo rate and Score keeping the length of the paper in mind. Given that we have considered two policy variables, we have estimated two different VAR models. The ordering of the variables in each of the models is slightly varied depending on the cross correlation matrix. The data is obtained from RBI, Handbook of Statistics for the Indian Economy and various issues of RBI Bulletin.

Our empirical strategy is as follows. First we specify the variables to be estimated and then estimate the VAR model. The variables are estimated in levels as the goal of the VAR analysis is to study interrelationships among variables and not to determine efficient estimates Sims (1980)는 . Specifying a VAR in differences would lead to losing information on the comovement of variables. Lastly estimating VAR with non-stationary variables may lead to some loss of efficiency but still the consistency properties would remain intact (Sims, Stock \& Watson 1990) ${ }^{12}$.

While estimating VAR models two issues are important (a) lag structure \& (b) serial correlation. In our model lags are selected on the basis of (AIC) \& (SBC) criteria. Lags having the smallest value of these are selected. In case of uncertainity, AIC criteria is given preference. Serial correlation of the estimated models is checked through autocorrelation LM test.

Once the model is estimated we use the impulse response analysis to look into the dynamic response of each variable to shocks in different policy variables within two standard error bands. Thereafter we compute the forecast error variance decomposition which provides the proportion of total forecast error variance of each variable that is caused by each of the shocks or disturbances in the system.

\section{Findings}

\subsection{Model 1 - Price Based Instrument as the Policy Rate}

Here we take the repo rate (RR) as the policy rate. The ordering of the variables are - RR, CMR, GS1, GS, EX, LSen based on the structure of the cross correlation matrix. The optimal lag length selected is 2 . 
The impulse responses of the VAR model show that a positive shock on RR leads to an increase in the CMR (Figure 4), the peak effect occurring after three months. After that it begins to fall and then stabilises after seven months but has a perceptible effect even after ten months. The impulse response for GS1 (Figure 5) clearly follows that of CMR but it peaks a little earlier and stabilises after five months. The response of GS (Figure 6) is also positive but less than the previous two implying that the RR affects the short end of the market more and it slowly spreads to the rates of instruments of higher maturities. This corroborates the result of the RBI (2011) study which says that the impact of the interest rate channel of monetary transmission varies across the segments of the financial markets, it is the strongest in the money markets.

Coming to the impact of RR on EX (Figure 7) we see that there is a significant appreciation of the exchange rate which peaks in the fourth month and thereby decreases but the effect persists even after sixteen months. This may be due to the presence of quantity channel. It works when central banks (of mostly advanced economies) engage in quantitative easing, their currencies depreciate. This leads to a flood of liquidity in emerging market economies (EMEs) in search of yields causing an appreciation in the latter's exchange rate.

Lastly the effect of LSen (Figure 8) becomes negative in the second month and it continues to remain so for the remaining months. However the magnitude of the effect of RR on LSen is negligible implying that a positive impact on policy rates has a very weak effect on the asset market. This shows that the asset price channel is weak in India during the estimation. The reason may be that the Indian economy has more of a bank based system rather than a market based one. (Bhattacharya \& Sensarma 2007) ${ }^{6}$.

Coming to Forecast Error Variance Decomposition analysis of the model, we notice that variations in CMR are explained by CMR, GS1, RR, GS, EX, LSen in that order (Table 1). This implies that the repo rate and other short term interest rates have a strong influence on call money rates. The same results are obtained for variance decompositions of GS \& GS1 (Table 2 \& 3) showing that price based instruments of monetary policy have a significant influence on interest rates of different maturities. Together with this, other interest rates of different maturities explain part of the variance indicating increased financial integration for the Indian economy similar to the (Bhoi \& Dhal 1998) $)^{4}$ study.
Variation in EX is explained by EX, LSen, RR, CMR, GS1, GS implying that stock markets have a significant influence on the exchange rate along with the repo rate (Table 4) This also indicate the presence of the exchange rate channel of monetary policy during the estimating period. Lastly variations in LSen is explained by LSen, CMR, GS, RR, GS1, EX (Table 5) The impact of policy rates and other interest rates are low implying that monetary transmission through price instruments on the asset market is imperfect.

\subsection{Model 2 - Overall Stance of Monetary Policy as the Policy Variable}

The policy variable taken includes both price (Repo) \& quantity (CRR \& SLR) instruments which is represented by Score. The following ordering of the variables is considered for the VAR analysis depending on the cross correlation matrix - Score, GS1, CMR, GS, EX, LSen. The optimal lag length chosen is 3 .

The impulse response function show that a positive shock in Score leads to an increase in GS1 (Figure 9), the peak effect occurring after three months and then it slowly dies down by the seventh month. The response for CMR (Figure 10) is slightly less than GS1. It peaks after two months, remains steady till the fourth month and then dies down by the fifth month. The reason may be that changes in CRR \& SLR affects liquidity of banks and so the effect on government securities is more than short term money markets. Secondly under the new LAF put in place in September 2014, more importance was given to term repos rather than overnight repos thereby decreasing the excessive importance of money market in liquidity management.

Coming to the effect of GS (Figure 11), the response is initially negative which turns into positive from the sixth month but the effect is negligible after that. This implies that changes in overall stance of monetary policy affects the interest rates of longer maturity instruments slowly as it requires time for the financial market agents to interpret RBI's actions. Another reason may be that there is a significant increase in nonresident holding of domestic securities during the estimation period. This has exposed the domestic bond markets to rising comovements with bond yields of other countries especially developed ones.

The response of exchange rate (Figure 12) is initially a depreciation which peaks in the second month but slowly declines and by the end of the fifth month turns 


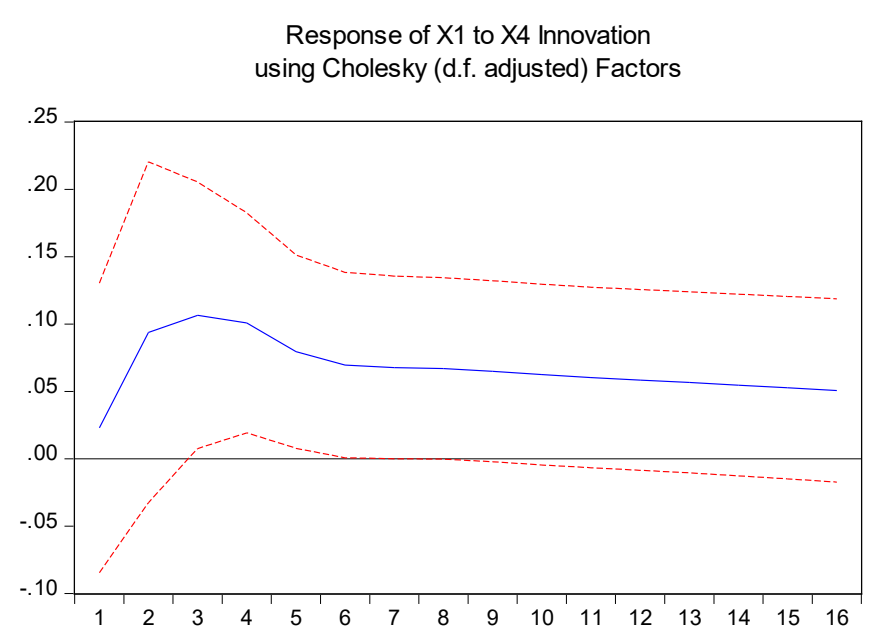

Source: Author's calculation.

Figure 4. Response of CMR to one SD RR Innovation.

Response of X8 to X4 Innovation using Cholesky (d.f. adjusted) Factors

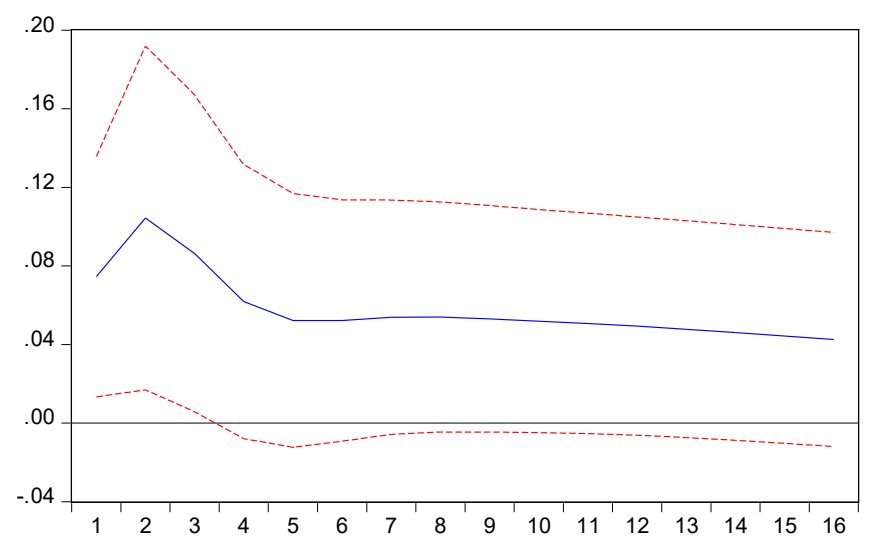

Source: Author's calculation.

Figure 5. Response of GS1 to one SD RR Innovation.

Response of $X 7$ to $X 4$ Innovation using Cholesky (d.f. adjusted) Factors

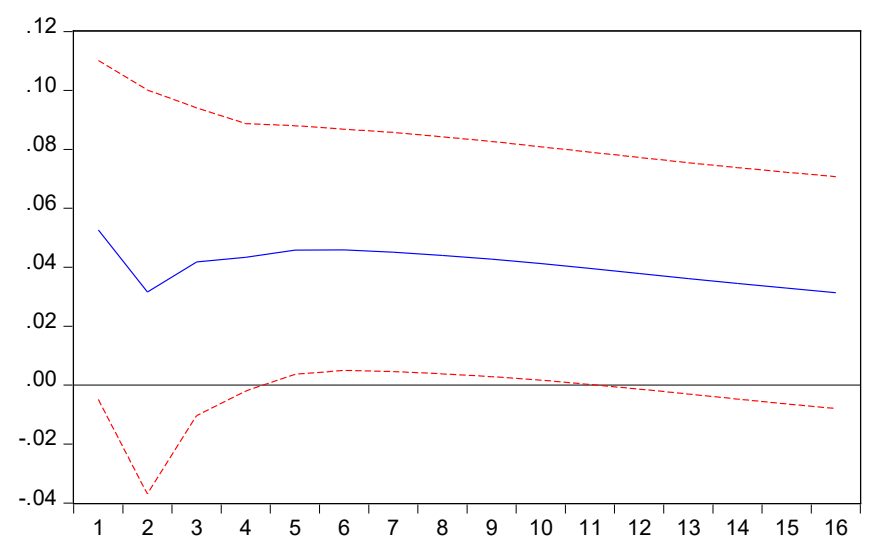

Source: Author's calculation.

Figure 6. Response of GS to one SD RR Innovation. 
Response of X9 to X4 Innovation using Cholesky (d.f. adjusted) Factors

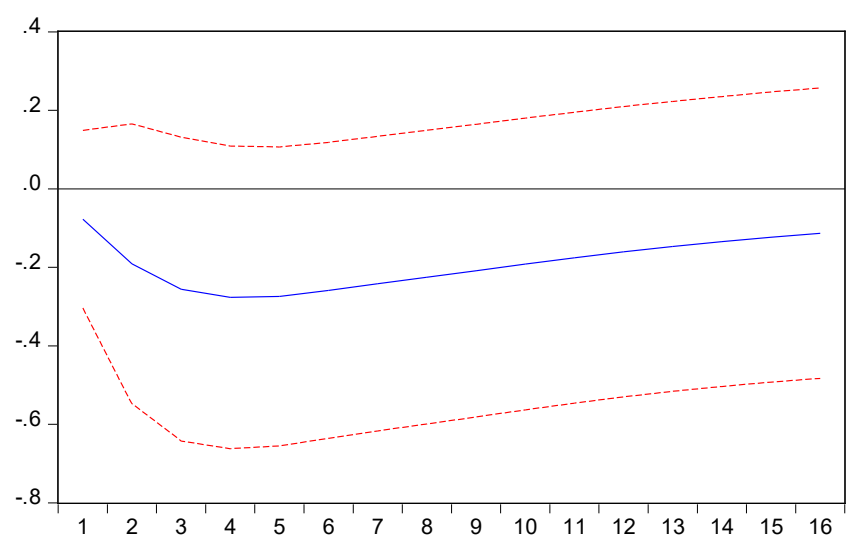

Source: Author's calculation.

Figure 7. Response of EX to one SD RR Innovation.

Response of $X 13$ to $X 4$ Innovation using Cholesky (d.f. adjusted) Factors

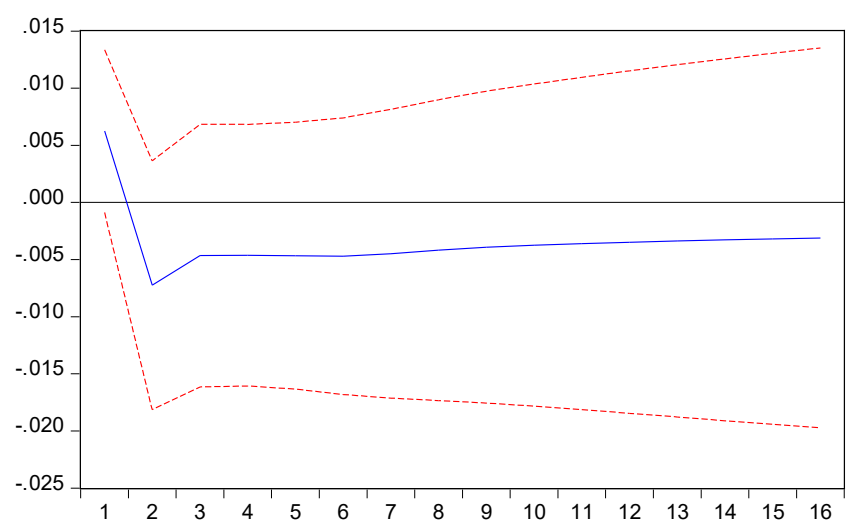

Source: Author's calculation.

Figure 8. Response of LSen to one SD RR Innovation.

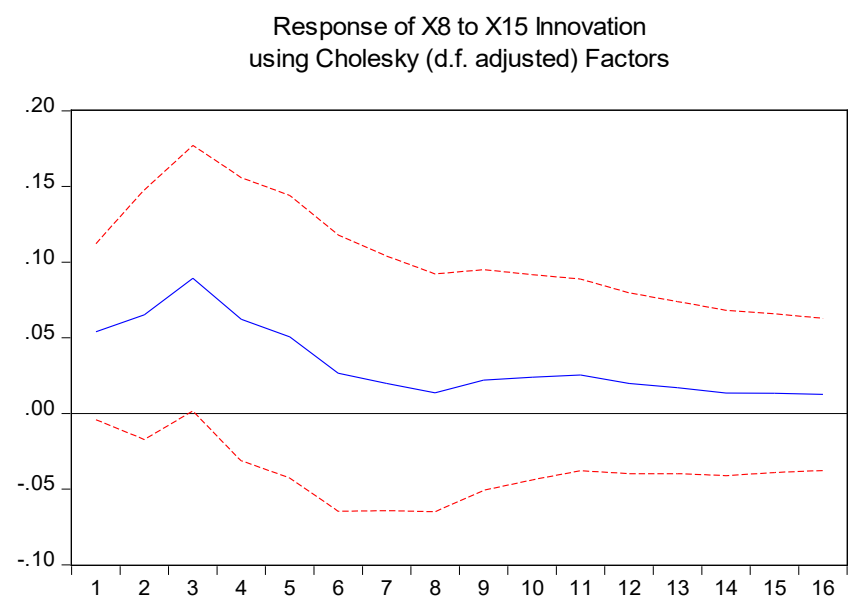

Source: Author's calculation.

Figure 9. Response of GS1 to one SD Score Innovation. 


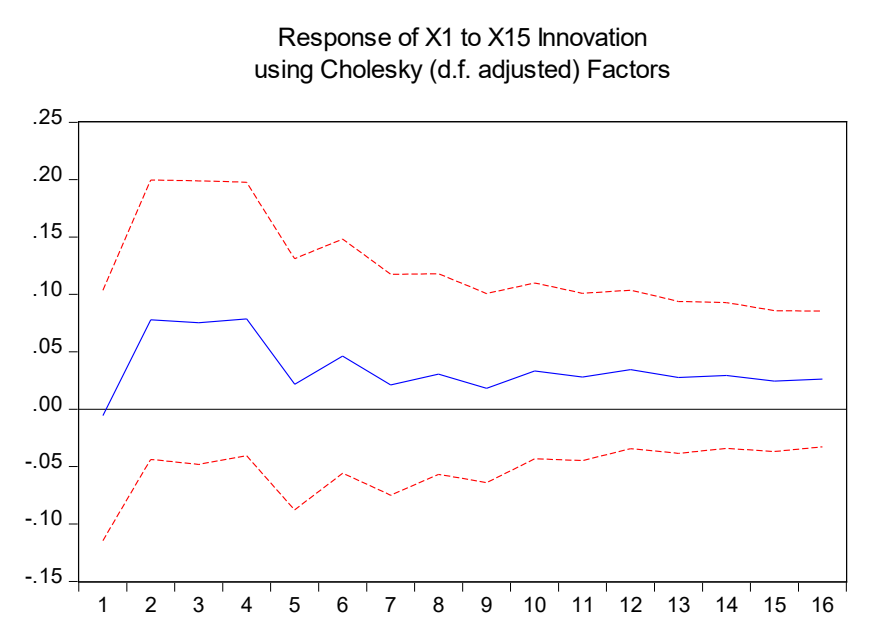

Source: Author's calculation.

Figure 10. Response of CMR to one SD Score Innovation.

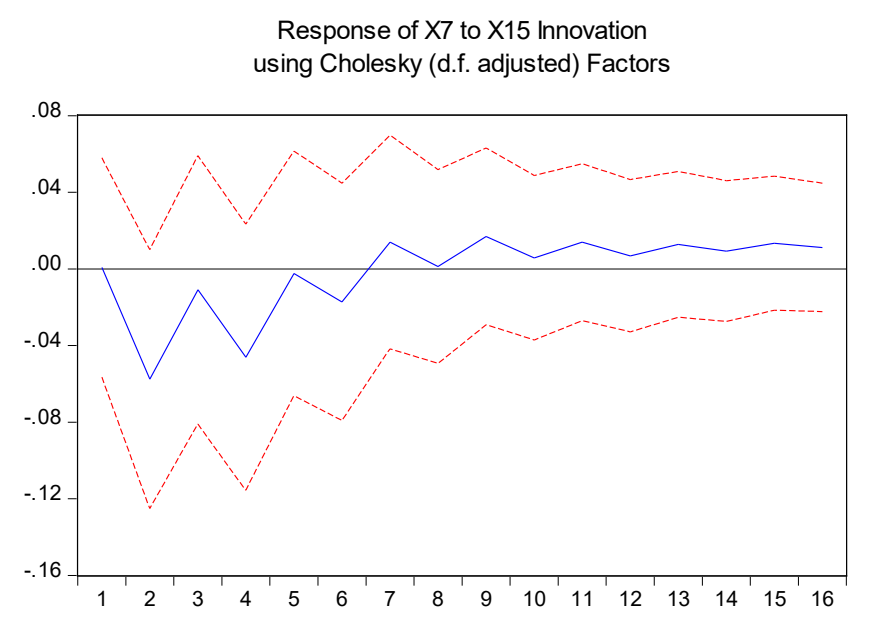

Source: Author's calculation.

Figure 11. Response of GS to one SD Score Innovation.

Response of X9 to X15 Innovation using Cholesky (d.f. adjusted) Factors

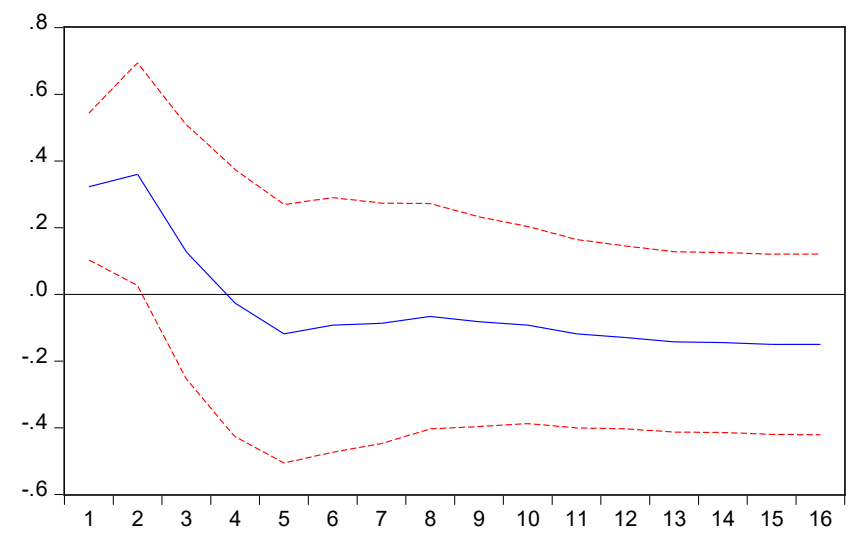

Source: Author's calculation.

Figure 12. Response of EX to one SD Score Innovation. 
Response of X13 to X15 Innovation

using Cholesky (d.f. adjusted) Factors

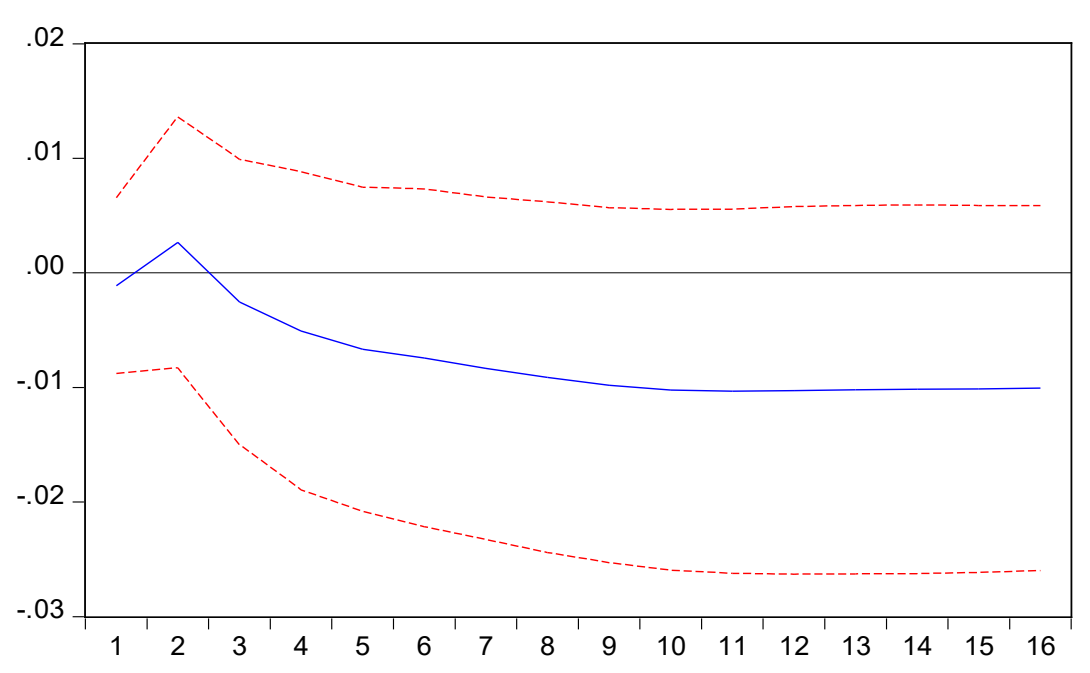

Source: Author's calculation.

Figure 13. Response of LSen to one SD Score Innovation.

Table 1. Forecast Decomposition of CMR (Model 1)

\begin{tabular}{|c|c|c|c|c|c|c|c|}
\hline Period & S.E. & RR & CMR & GS1 & GS & EX & LSen \\
\hline 1 & 0.126014 & 0.221259 & 99.77874 & 0.000000 & 0.000000 & 0.000000 & 0.000000 \\
\hline 2 & 0.173817 & 3.033939 & 79.71563 & 14.49338 & 0.241918 & 2.429977 & 0.085157 \\
\hline 3 & 0.215356 & 5.560628 & 65.95185 & 23.77223 & 0.466047 & 3.522111 & 0.727138 \\
\hline 4 & 0.250892 & 7.513244 & 60.30538 & 25.92994 & 0.978998 & 3.938208 & 1.334226 \\
\hline 5 & 0.280109 & 8.439743 & 57.41072 & 26.09072 & 2.444434 & 3.899440 & 1.714943 \\
\hline 6 & 0.304220 & 9.018661 & 55.15868 & 26.14316 & 3.942841 & 3.717966 & 2.018692 \\
\hline 7 & 0.324690 & 9.553636 & 53.16724 & 26.23321 & 5.154999 & 3.551345 & 2.339571 \\
\hline 8 & 0.342516 & 10.06743 & 51.43642 & 26.18786 & 6.171189 & 3.441282 & 2.695827 \\
\hline 9 & 0.358325 & 10.52909 & 49.95887 & 25.99917 & 7.032566 & 3.400093 & 3.080207 \\
\hline 10 & 0.372526 & 10.93459 & 48.68132 & 25.73793 & 7.727902 & 3.427936 & 3.490313 \\
\hline
\end{tabular}

Table 2. Forecast Decomposition of GS1 (Model 1)

\begin{tabular}{|c|c|c|c|c|c|c|c|}
\hline Period & S.E. & RR & CMR & GS1 & GS & EX & LSen \\
\hline 1 & 0.126014 & 6.978574 & 4.170151 & 88.85127 & 0.000000 & 0.000000 & 0.000000 \\
\hline 2 & 0.173817 & 10.70191 & 2.700084 & 84.50476 & 0.117836 & 1.867593 & 0.107817 \\
\hline 3 & 0.215356 & 12.24995 & 3.435379 & 78.50165 & 2.384732 & 3.221436 & 0.206852 \\
\hline 4 & 0.250892 & 12.35811 & 5.154768 & 72.05824 & 6.895578 & 3.320074 & 0.213232 \\
\hline 5 & 0.280109 & 12.29807 & 6.126382 & 67.45798 & 10.85184 & 3.060129 & 0.205602 \\
\hline 6 & 0.304220 & 12.48601 & 6.360949 & 64.55529 & 13.52757 & 2.858126 & 0.212053 \\
\hline 7 & 0.324690 & 12.86327 & 6.345495 & 62.41061 & 15.35981 & 2.778752 & 0.242060 \\
\hline 8 & 0.342516 & 13.30992 & 6.284272 & 60.63597 & 16.65666 & 2.817225 & 0.295957 \\
\hline 9 & 0.358325 & 13.76414 & 6.217851 & 59.14187 & 17.54683 & 2.956350 & 0.372955 \\
\hline 10 & 0.372526 & 14.20864 & 6.147636 & 57.88255 & 18.11404 & 3.171198 & 0.475934 \\
\hline
\end{tabular}

Source: Author's calculation. 
Table 3. Forecast Decomposition of GS (Model 1)

\begin{tabular}{|c|c|c|c|c|c|c|c|}
\hline Period & S.E. & RR & CMR & GS1 & GS & EX & LSen \\
\hline 1 & 0.126014 & 4.006224 & 0.001059 & 3.982007 & 92.01071 & 0.000000 & 0.000000 \\
\hline 2 & 0.173817 & 4.228007 & 0.729674 & 3.756634 & 90.11121 & 1.133723 & 0.040748 \\
\hline 3 & 0.215356 & 5.113934 & 1.122518 & 3.925711 & 87.96604 & 1.821001 & 0.050797 \\
\hline 4 & 0.250892 & 6.188304 & 1.136246 & 4.381283 & 85.67419 & 2.573030 & 0.046952 \\
\hline 5 & 0.280109 & 7.375078 & 1.119130 & 4.831774 & 83.32376 & 3.301673 & 0.048581 \\
\hline 6 & 0.304220 & 8.516720 & 1.113389 & 5.212676 & 81.06640 & 4.023080 & 0.067735 \\
\hline 7 & 0.324690 & 9.566142 & 1.115019 & 5.555221 & 78.93093 & 4.721406 & 0.111280 \\
\hline 8 & 0.342516 & 10.51445 & 1.118457 & 5.871354 & 76.92337 & 5.386364 & 0.186003 \\
\hline 9 & 0.358325 & 11.36057 & 1.123537 & 6.153241 & 75.05523 & 6.009506 & 0.297917 \\
\hline 10 & 0.372526 & 12.10413 & 1.131529 & 6.392426 & 73.33175 & 6.589124 & 0.451050 \\
\hline
\end{tabular}

Table 4. Forecast Decomposition of EX (Model 1)

\begin{tabular}{|c|c|c|c|c|c|c|c|}
\hline Period & S.E. & RR & CMR & GS1 & GS & EX & LSen \\
\hline 1 & 0.126014 & 0.571319 & 1.964554 & 2.644716 & 0.205421 & 94.61399 & 0.000000 \\
\hline 2 & 0.173817 & 1.696749 & 0.832890 & 3.068088 & 0.394638 & 93.83989 & 0.167749 \\
\hline 3 & 0.215356 & 2.809248 & 1.107162 & 2.754927 & 1.059836 & 91.65704 & 0.611790 \\
\hline 4 & 0.250892 & 3.666716 & 1.615509 & 2.541377 & 1.880816 & 88.94074 & 1.354840 \\
\hline 5 & 0.280109 & 4.299750 & 1.803481 & 2.468577 & 2.546763 & 86.59281 & 2.288620 \\
\hline 6 & 0.304220 & 4.741790 & 1.814161 & 2.419978 & 3.103742 & 84.56167 & 3.358657 \\
\hline 7 & 0.324690 & 5.062683 & 1.762627 & 2.346578 & 3.577434 & 82.69089 & 4.559786 \\
\hline 8 & 0.342516 & 5.303995 & 1.687605 & 2.259468 & 3.954553 & 80.90561 & 5.888772 \\
\hline 9 & 0.358325 & 5.482129 & 1.604985 & 2.174290 & 4.220905 & 79.18719 & 7.330500 \\
\hline 10 & 0.372526 & 5.605683 & 1.526739 & 2.096680 & 4.382388 & 77.52555 & 8.862963 \\
\hline
\end{tabular}

Source: Author's calculation.

Table 5. Forecast Decomposition of LSen (Model 1)

\begin{tabular}{|c|c|c|c|c|c|c|c|}
\hline Period & S.E. & RR & CMR & GS1 & GS & EX & LSen \\
\hline 1 & 0.126014 & 3.690325 & 2.747264 & 0.258764 & 3.876128 & 0.044625 & 89.38290 \\
\hline 2 & 0.173817 & 3.901265 & 2.180344 & 0.594018 & 10.53582 & 0.370544 & 82.41801 \\
\hline 3 & 0.215356 & 3.264609 & 2.467459 & 0.842883 & 9.493998 & 0.269380 & 83.66167 \\
\hline 4 & 0.250892 & 2.960310 & 3.347016 & 0.677329 & 8.628197 & 0.205704 & 84.18144 \\
\hline 5 & 0.280109 & 2.805884 & 3.917256 & 0.574274 & 7.642363 & 0.169113 & 84.89111 \\
\hline 6 & 0.304220 & 2.710809 & 4.317549 & 0.553507 & 6.882394 & 0.144373 & 85.39137 \\
\hline 7 & 0.324690 & 2.617995 & 4.684830 & 0.537773 & 6.345098 & 0.128927 & 85.68538 \\
\hline 8 & 0.342516 & 2.519327 & 5.017472 & 0.513079 & 5.971691 & 0.123948 & 85.85448 \\
\hline 9 & 0.358325 & 2.422850 & 5.284995 & 0.484528 & 5.695904 & 0.130956 & 85.98077 \\
\hline 10 & 0.372526 & 2.334292 & 5.483630 & 0.454966 & 5.476453 & 0.149665 & 86.10099 \\
\hline
\end{tabular}


Table 6. Forecast Decomposition of GS1 (Model 2)

\begin{tabular}{|c|c|c|c|c|c|c|c|}
\hline Period & S.E. & Score & GS1 & CMR & GS & EX & LSen \\
\hline 1 & 0.252690 & 4.157543 & 95.84246 & 0.000000 & 0.000000 & 0.000000 & 0.000000 \\
\hline 2 & 0.300600 & 5.043465 & 93.20384 & 0.225379 & 0.012461 & 1.514698 & 0.000160 \\
\hline 3 & 0.359922 & 8.148272 & 80.17022 & 0.416639 & 4.749129 & 4.911361 & 1.604383 \\
\hline 4 & 0.377223 & 8.322144 & 68.03528 & 1.328595 & 14.13638 & 5.470375 & 2.707223 \\
\hline 5 & 0.382998 & 8.292495 & 63.79741 & 1.465728 & 18.71676 & 4.918756 & 2.808848 \\
\hline 6 & 0.384960 & 7.892776 & 64.58419 & 1.404409 & 18.94189 & 4.535175 & 2.641569 \\
\hline 7 & 0.387409 & 7.566131 & 65.80921 & 1.481255 & 18.30696 & 4.328767 & 2.507674 \\
\hline 8 & 0.389729 & 7.340987 & 66.24182 & 1.758216 & 17.92164 & 4.313249 & 2.424080 \\
\hline 9 & 0.391987 & 7.278932 & 66.00639 & 2.023347 & 17.84477 & 4.489926 & 2.356633 \\
\hline 10 & 0.392739 & 7.252237 & 65.56430 & 2.167534 & 17.89430 & 4.829450 & 2.292182 \\
\hline
\end{tabular}

Source: Author's calculation.

Table 7. Forecast Decomposition of CMR (Model 2)

\begin{tabular}{|c|c|c|c|c|c|c|c|}
\hline Period & S.E. & Score & GS1 & CMR & GS & EX & LSen \\
\hline 1 & 0.252690 & 0.012584 & 5.092805 & 94.89461 & 0.000000 & 0.000000 & 0.000000 \\
\hline 2 & 0.300600 & 1.962427 & 21.66814 & 74.55144 & 0.532772 & 0.279854 & 1.005362 \\
\hline 3 & 0.359922 & 3.214322 & 27.86695 & 63.77568 & 1.854036 & 2.424922 & 0.864089 \\
\hline 4 & 0.377223 & 4.320291 & 27.45639 & 57.23470 & 5.045663 & 3.649610 & 2.293340 \\
\hline 5 & 0.382998 & 4.027860 & 26.76748 & 52.73292 & 9.648275 & 3.432209 & 3.391249 \\
\hline 6 & 0.384960 & 4.207874 & 27.11936 & 49.42358 & 12.31744 & 3.218067 & 3.713689 \\
\hline 7 & 0.387409 & 4.117778 & 28.38790 & 47.45989 & 13.14364 & 3.088123 & 3.802669 \\
\hline 8 & 0.389729 & 4.135545 & 29.53139 & 45.89679 & 13.44194 & 3.041185 & 3.953155 \\
\hline 9 & 0.391987 & 4.086565 & 30.33443 & 44.92397 & 13.50816 & 3.076073 & 4.070807 \\
\hline 10 & 0.392739 & 4.190162 & 30.71816 & 44.10483 & 13.61953 & 3.180243 & 4.187069 \\
\hline
\end{tabular}

Table 8. Forecast Decomposition of GS (Model 2)

\begin{tabular}{|c|c|c|c|c|c|c|c|}
\hline Period & S.E. & Score & GS1 & CMR & GS & EX & LSen \\
\hline 1 & 0.252690 & 0.000858 & 5.301503 & 0.167418 & 94.53022 & 0.000000 & 0.000000 \\
\hline 2 & 0.300600 & 3.442181 & 7.629672 & 0.184921 & 86.76231 & 1.954314 & 0.026599 \\
\hline 3 & 0.359922 & 2.882965 & 8.579639 & 0.158965 & 86.34173 & 1.934753 & 0.101948 \\
\hline 4 & 0.377223 & 4.239182 & 10.04297 & 0.940872 & 82.33436 & 2.323345 & 0.119272 \\
\hline 5 & 0.382998 & 3.998905 & 11.43568 & 1.595201 & 79.98351 & 2.869626 & 0.117078 \\
\hline 6 & 0.384960 & 4.055327 & 12.71061 & 2.008851 & 77.73100 & 3.370876 & 0.123341 \\
\hline 7 & 0.387409 & 4.034685 & 13.76209 & 2.292395 & 75.91252 & 3.869475 & 0.128842 \\
\hline 8 & 0.389729 & 3.908831 & 14.69146 & 2.496413 & 74.46303 & 4.300514 & 0.139758 \\
\hline 9 & 0.391987 & 3.955833 & 15.43309 & 2.610163 & 73.07537 & 4.714640 & 0.210906 \\
\hline 10 & 0.392739 & 3.871721 & 16.08314 & 2.719615 & 71.96343 & 5.079450 & 0.282642 \\
\hline
\end{tabular}

Source: Author's calculation. 
Table 9. Forecast Decomposition of EX

\begin{tabular}{|c|c|c|c|c|c|c|c|}
\hline Period & S.E. & Score & GS1 & CMR & GS & EX & LSen \\
\hline 1 & 0.252690 & 10.06377 & 0.714954 & 0.121047 & 0.007399 & 89.09283 & 0.000000 \\
\hline 2 & 0.300600 & 9.928030 & 2.210457 & 1.245227 & 0.142756 & 86.44269 & 0.030838 \\
\hline 3 & 0.359922 & 7.432453 & 2.007688 & 1.611038 & 0.166316 & 88.69640 & 0.086104 \\
\hline 4 & 0.377223 & 6.226886 & 1.815940 & 1.660108 & 0.142900 & 90.08139 & 0.072778 \\
\hline 5 & 0.382998 & 5.904206 & 1.682872 & 1.784139 & 0.250429 & 89.88211 & 0.496241 \\
\hline 6 & 0.384960 & 5.652542 & 1.588697 & 1.949659 & 0.399049 & 88.81362 & 1.596436 \\
\hline 7 & 0.387409 & 5.480403 & 1.551064 & 2.105035 & 0.455351 & 87.19690 & 3.211245 \\
\hline 8 & 0.389729 & 5.303202 & 1.597532 & 2.295625 & 0.436924 & 85.32324 & 5.043480 \\
\hline 9 & 0.391987 & 5.192531 & 1.705566 & 2.498316 & 0.427031 & 83.16822 & 7.008331 \\
\hline 10 & 0.392739 & 5.129377 & 1.831427 & 2.660905 & 0.448974 & 80.91048 & 9.018841 \\
\hline
\end{tabular}

Table 10. Forecast Decomposition of LSen

\begin{tabular}{|c|c|c|c|c|c|c|c|}
\hline Period & S.E. & Score & GS1 & CMR & GS & EX & LSen \\
\hline 1 & 0.252690 & 0.103021 & 2.464824 & 5.167212 & 1.595978 & 0.068539 & 90.60042 \\
\hline 2 & 0.300600 & 0.337464 & 1.653096 & 4.071308 & 12.23048 & 1.198612 & 80.50904 \\
\hline 3 & 0.359922 & 0.413502 & 2.070996 & 4.365646 & 12.68722 & 1.739955 & 78.72268 \\
\hline 4 & 0.377223 & 0.858153 & 2.186486 & 4.286044 & 12.16114 & 2.304008 & 78.20417 \\
\hline 5 & 0.382998 & 1.481898 & 1.840076 & 4.367913 & 10.93537 & 2.462544 & 78.91220 \\
\hline 6 & 0.384960 & 2.082032 & 1.582037 & 4.304050 & 9.642716 & 2.602775 & 79.78639 \\
\hline 7 & 0.387409 & 2.711173 & 1.394384 & 4.259226 & 8.517022 & 2.736544 & 80.38165 \\
\hline 8 & 0.389729 & 3.346944 & 1.234798 & 4.277070 & 7.638491 & 2.818206 & 80.68449 \\
\hline 9 & 0.391987 & 3.990912 & 1.108891 & 4.284623 & 6.958921 & 2.815329 & 80.84132 \\
\hline 10 & 0.392739 & 4.606978 & 1.014139 & 4.250190 & 6.409656 & 2.764163 & 80.95487 \\
\hline
\end{tabular}

Source: Author's calculation.

into appreciation. The reason for this phenomenon can be due to the fact that exchange rate changes in EMEs can occur due to several channels. First the quantity channel which is explained in the previous section. Second the balance sheet channel which says that changes in bond yield differentials and equity variations may encourage investors to alter their asset positions leading to exchange rate changes. Lastly the expectations channel where expectations of announcements on changes in monetary policy stance can initiate sizeable exchange rate adjustments. So the effect of monetary policy stance on exchange rates depends on the relative strengths of these channels. The score variable affects the stock index negatively (Figure 13) as a policy tightening leads to a decrease in economic activity.

Overall the results are similar to the previous model although the magnitude of the impact is less compared to the price instrument. The reason may be that in some cases the price instrument and quantity instrument have been used in different directions. Secondly expectations of financial market agents may be slow in adjusting when a combination of policies is used especially during a period when global financial spillovers have an effect on the domestic financial markets (Patra et al., 2016) $\frac{13}{\text {. }}$.

The forecast error variance decomposition analysis of Model 2 shows variations in GS1 is explained by GS1, GS, Score, EX, LSen, CMR (Table 6). For CMR it is CMR, GS, GS1, Score, LSen, EX (Table 7). For GS1 it is GS1, GS, EX, Score, CMR, LSen (Table 8). From this we can interpret that interest rates are influenced both by interest rates of other maturities as well as the overall stance of monetary policy. Variance Decomposition of EX is explained by EX, LSen, Score, CMR, GS1, GS (Table 9). So exchange rate variations are explained both by stock prices and 
monetary policy stance. During the estimation period there was a growing importance of portfoio investment flows which led to episodes of volatility in both the forex market and the equity market. This may be the reason behind the strong comovement of the forex market and the stock market. Lastly LSen is explained by LSen, GS, Score, CMR, EX, GS1 (Table 10).

\section{Conclusion}

The policies undertaken during the process of financial liberalisation have led to the integration of financial markets in India. An integrated financial market makes the pass through from the policy rates to market determined interest rates much easier and thereby improves the efficacy of the interest rate channel of monetary transmission.

The study analyses the impact of policy rate changes and changes in the composite index comprising of quantity instruments and policy rates on the rates of various markets in India from May 2011 through March 2018. The results indicate that changes in the policy instruments by the RBI is transmitted quickly in the short end of the financial market namely the call money market and one year government securities market. The effect on ten year government securities is slightly delayed reflecting the fact that the impact of interest rate channel of monetary transmission varies across the segments of the financial markets and the strongest effect is felt in the money market.

The effect of a change in the repo rate causes an immediate appreciation of the exchange rate due to quantitative easing pursued by developed countries. When the composite index is taken the effect is an initial depreciation which later turns into appreciation. This may be due to the fact that exchange rate changes in EMEs are influenced by various channels namely quantity channel, balance sheet channel and expectation channel. Lastly the effect of policy rate variable and composite index on the sensex is negative implying a policy tightening leads to a decrease in economic activity.

\section{References}

1. Ross, L. Financial Development and Economic Growth. Journal of Economic Literature. 1997; 35(2):686-726.
2. Ray, P and Prabu, E. Financial Development and Monetary Policy Transmission Across Financial Markets: What Do Daily Data tell for India. RBI Working Paper Series. 2013. WPS (DEPR): 04/2013.

3. Vasudevan, A and Menon, K. On Testing of Some Hypothesis Concerning the Transmission Mechanism of Monetary Policy: The Indian Experience. In the book, Money and Banking: Select Research Papers by the Economists of Reserve Bank of India edt. by A Vasudevan, Academic foundation. 1978.

4. Bhoi, BK, and Dhal, SC. Integration of financial markets in India: an empirical evaluation. RBI Occasional Papers. 1998; 19(4):345-80.

5. Jain, S, and Bhanumurthy, NR. Financial Markets Integration in India. Asia - Pacific Development Journal. 2005; 12(2):15-32.

6. Bhattacharya, I, and Sensarma, R. How effective are Monetary Policy Signals in India: Evidence from a SVAR model. Journal of Policy Modeling. 2007; 30(1):169-83.

7. Bhattacharya, I, Roy, M, Joshi, H, and Patra, MD. Money market microstructure and monetary policy: the Indian experience. Macroeconomics and Finance in Emerging Market Economies. 2009; 2(1):59-77.

8. Singh, B. How Asymmetric is the Monetary Policy Transmission to Financial Markets in India? RBI Occasional Paper. 2011; 32(2):1-37.

9. Reserve Bank of India (RBI). Report of the Working Group on Operating Procedures of Monetary Policy (Chairman: Deepak Mohanty), Mumbai Reserve Bank of India. 2011.

10. Das, A, Mishra, P, and Prabhala, N. The bank lending Channel of Monetary Transmission: New Evidence from India, cited in the paper, Monetary Transmission in Developing Countries: Evidence from India, in Ghate, C, \& Kletzer, K, M edt. Monetary Policy in India - A Modern Macroeconomics Perspective. Springer, 2015.

11. Sims, C, A. Macroeconomics and Reality. Econometrica. 1980; 48(1):1-48.

12. Sims, CA, Stock, JH \& Watson, MW. Inference in Linear Time Series Models with some Unit Roots. Econometrica. 1990; 58(1):113-44.

13. Patra, MD, Kapur, M, Kavediya, R, and Lokare, SM. Liquidity Management and Monetary Policy: from Corridor Play to Markmanship. In Ghate, C \& Kletzer K M edt. Monetary Policy in India - A Modern Macroeconomic Perspective. Springer, 2016. 